\title{
Hydrogen production for fuel cell application in an autothermal micro-channel reactor
}

\author{
Pierre Reuse $^{\mathrm{a}}$, Albert Renken ${ }^{\mathrm{a}, *}$, Katja Haas-Santo ${ }^{\mathrm{b}}$, Oliver Görke ${ }^{\mathrm{b}}$, Klaus Schubert ${ }^{\mathrm{b}}$ \\ a Swiss Federal Institute of Technology, EPFL-LGRC, 1015 Lausanne, Switzerland \\ ${ }^{\mathrm{b}}$ Forschungszentrum Karlsruhe, Institut für Mikrofahrenstechnik, 76021 Karlsruhe, Germany
}

\begin{abstract}
Results concerning the coupling of the steam reforming (SR) and total oxidation (TOX) of methanol in a two-passage reactor are presented. A commercially available copper based catalyst is used for the steam reforming. For the total oxidation, a highly active cobalt oxide catalyst was developed. Both catalysts are used in form of thin layers immobilized on the wall of the micro-channels. Reactor design and operating conditions are based on kinetic models developed under isothermal conditions in micro-structured reactors. For the oxidation reaction, complete conversion of methanol (>99\%) at temperatures higher than $250{ }^{\circ} \mathrm{C}$ is observed. For the steam reforming, the hydrogen and $\mathrm{CO}_{2}$ selectivity is higher than $96 \%$ for methanol conversion up to $90 \%$. Besides the steady state, the dynamic behavior of the coupled system is studied. It is shown that the transient behavior is mainly determined by the thermal inertia of the system.

(C) 2004 Elsevier B.V. All rights reserved.
\end{abstract}

Keywords: Hydrogen; Micro-structured reactor; Autothermal; Coupling

\section{Introduction}

Due to their high energy storage density, liquid fuels are attractive for fuel cell application. Hydrogen for fuel cells can be produced in mobile units by steam reforming (SR). However, traditional reactors with randomly packed catalytic beds show limitations in heat and mass transfer and are not able to fulfill the dynamic demands for fuel cell systems with respect to load change and part load. In addition, the highly endothermic reforming reaction needs an important energy supply, which may lead to the development of pronounced axial and radial temperature profiles in the reactor.

Micro-structured reactors are much more suitable for the distributed production of hydrogen compared to conventional systems. They are characterized by three dimensional structures in the sub-millimeter range. Mainly multi-channel reactors are currently used with channel diameters between 10 and several hundred micrometers. Therefore, one of the main features of micro-structured reactors is their high surface to volume ratio which is several orders of magnitude higher compared to traditional chemical reactors. Micro-structured multi-channel reactors work under laminar flow conditions demonstrating low pressure drop compared to randomly fixed beds. The short radial diffusion times

\footnotetext{
* Corresponding author. Tel.: +41-21-693-3181; fax: +41-21-693-3190. E-mail address: albert.renken@epfl.ch (A. Renken).
}

lead to narrow residence time distribution of the gases. This allows optimizing the contact time of the reactants avoiding the formation of unwanted by-products. Moreover, the short residence time $(<0.1 \mathrm{~s})$ allows a quick response to dynamic changes in the inlet conditions $[1,2]$. For non-stationary operations of the reactor, this feature is essential.

There are several "primary fuels" as potential hydrogen sources for proton exchange membrane fuel cells used in automotive propulsion [3]. Steam reforming of methanol (Eq. (1)) enables the production of hydrogen at relatively low temperatures in the range of $230-300^{\circ} \mathrm{C}$. Therefore, only a relatively small amount of carbon monoxide $(<2 \%)$ is formed.

$$
\mathrm{CH}_{3} \mathrm{OH}+\mathrm{H}_{2} \mathrm{O} \rightarrow \mathrm{CO}_{2}+3 \mathrm{H}_{2} \quad\left(\Delta_{\mathrm{r}} H^{250^{\circ} \mathrm{C}}=59.5 \mathrm{~kJ} / \mathrm{mol}\right)
$$

Usual catalysts for this reaction are copper based. The presence of zinc oxide was found to be essential for the catalyst stability under reaction conditions [4]. As reported by numerous authors, a water to methanol molar ratio higher than 1 is beneficial for the catalyst activity and enhances the carbon dioxide selectivity [5,6]. At temperatures above $300^{\circ} \mathrm{C}$, catalyst deactivation can no longer be neglected and diminishes the reactor performance [7]. Therefore, working temperature has to be carefully chosen, taking into account the desired lifetime of the catalyst. 
As methanol steam reforming is an endothermic reaction, it is necessary to provide the reactor with sufficient heat-energy. The use of micro-structured reactors to bring heat directly to the core of the reactor, coupling the endothermic reforming with an exothermic combustion seems to be obvious. For this purpose, the off-gas of the fuel cell containing not converted hydrogen and methanol can be burned. In the present study, we focus on the total catalytic combustion of methanol, which is a highly exothermic reaction (Eq. (2)).

$$
\begin{aligned}
& \mathrm{CH}_{3} \mathrm{OH}+\frac{3}{2} \mathrm{O}_{2} \rightarrow \mathrm{CO}_{2}+2 \mathrm{H}_{2} \mathrm{O} \\
& \left(\Delta_{\mathrm{r}} H^{250^{\circ} \mathrm{C}}=673.2 \mathrm{~kJ} / \mathrm{mol}\right)
\end{aligned}
$$

The catalyst for total oxidation (TOX) must be highly active in the temperature range used for the steam reforming to guarantee complete conversion of the methanol. Therefore, synchronization of the minimal temperature for total oxida- tion with the maximal temperature of the steam reforming to ensure an acceptable catalyst lifetime has to be realized.

\section{Experimental}

\subsection{Micro-structured reactor}

Two different types of micro-structured reactors were used in the present study. For kinetic studies an isothermal reactor with 2500 micro-channels arranged on 25 plates is used. The channels are $40 \mathrm{~mm}$ long, $100 \mu \mathrm{m}$ deep, and $200 \mu \mathrm{m}$ large [7].

For the coupled methanol steam reforming/total oxidation a special two-passage micro-structured reactor was developed. The reactor consists of staked plates (Fig. 1A) and can be used as a co-current or counter-current heat exchanger
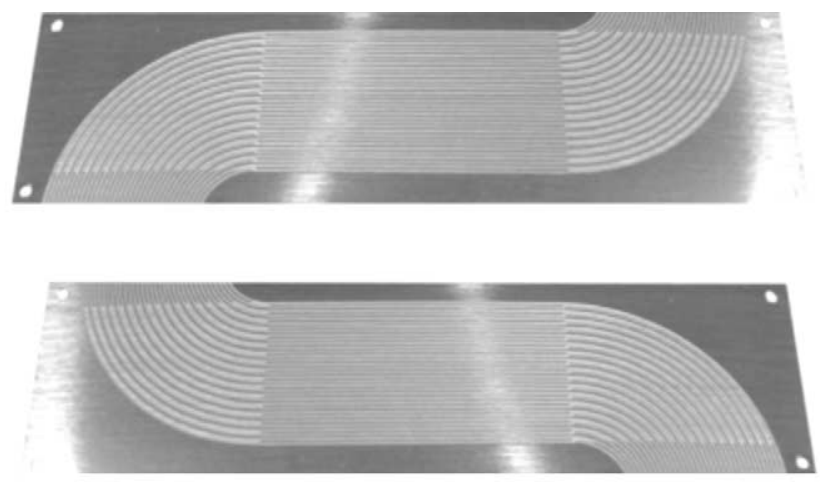

(A)

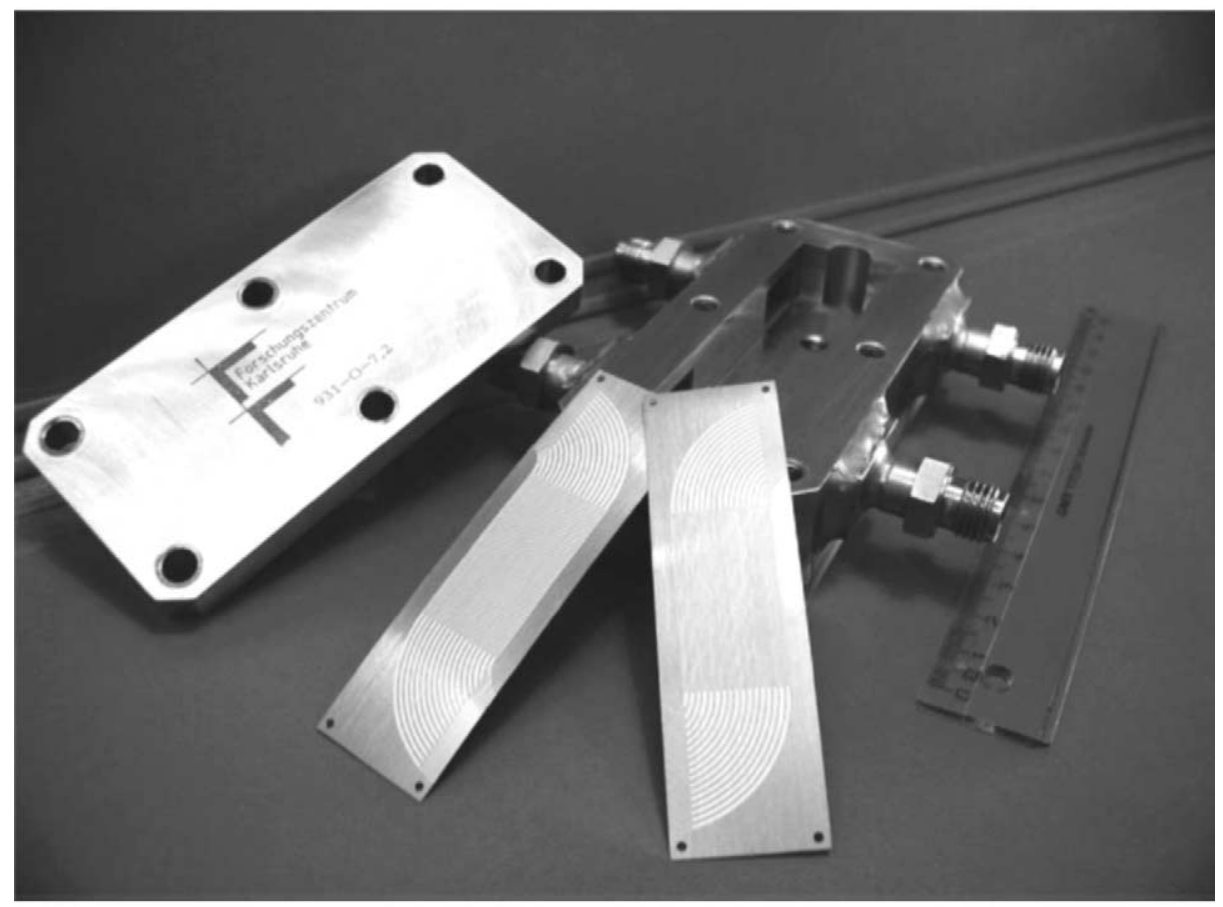

(B)

Fig. 1. (A) Micro-structured plates. (B) Housing of the two-passage micro-structured reactor (Research Center of Karlsruhe). 
(Fig. 1B) in which the reforming and oxidation reactions can be performed separately.

The plates are $78 \mathrm{~mm}$ long, $23 \mathrm{~mm}$ large, and $200 \mu \mathrm{m}$ thick. Channels are "S" shaped: 17 rounded channels are split up to give 34 straight channels with a total length of $30 \mathrm{~mm}$ long.

They are $320 \mu \mathrm{m}$ large and $100 \mu \mathrm{m}$ deep. Only the straight part is used for the reactions. The plates for the second reaction are the mirror image of the first one. All plates are staked together in the housing (Fig. 1B). In the middle of the stack a special plate, designed for temperature measurements, is inserted. A top plate is screwed in the housing to close the reactor hermetically. It is important to ensure that no interconnection between the oxidation and reforming reactors exists. Tracer experiments with helium in argon were performed to verify the tightness in between the reactor parts.

All micro-structured plates are made of aluminium containing stainless steel (DIN 1.4767, "FeCrAlloy"). By heating the alloy for approximately $5 \mathrm{~h}$ at $1000{ }^{\circ} \mathrm{C}$ a thin alumina film of approximately $5 \mu \mathrm{m}$ is formed on the surface [8]. This $\mathrm{Al}_{2} \mathrm{O}_{3}$ film greatly improves the adherence of the catalyst layers on the walls of the micro-channels.

For steam-reforming, the micro-structured channels are coated with a suspension of a commercial copper based catalyst (G-66MR, Südchemie). The catalyst was micro-milled to a particle size in the nano-meter range and used for the coating of the micro-channels [9]. The catalyst was calcined and activated by successive oxidation and reduction [9]. About $10 \mathrm{mg}$ of catalyst were deposited on each plate resulting in a catalytic layer of approximately $5 \mu \mathrm{m}$.

As the copper zinc oxide catalyst was found to be not active enough for complete oxidation of methanol at the temperature range used for steam reforming, a cobalt oxide catalyst was developed to coat the plates dedicated to catalytic combustion of methanol. The catalyst is synthesized as follows: straight parts of the channels were filled with an aqueous solution of cobalt nitrate (purum, Fluka Chemie AG, Buchs, Switzerland). After evaporation of water, the plates are heated to $120^{\circ} \mathrm{C}$ for 15 min melting the cobalt salt homogenizing the catalyst layers along the channels. Cobalt oxide is formed by calcination for $2 \mathrm{~h}$ at $350^{\circ} \mathrm{C}$ [10]. In this way $22 \mathrm{mg}$ of cobalt oxide were deposited on each plate. The catalytic plates were staked alternatively, in the housing (Fig. 1B).

The mounted reactor system is put in a box $(21 \mathrm{~cm} \times$ $16 \mathrm{~cm} \times 14 \mathrm{~cm}$ ) of Insulpac ${ }^{\circledR}$ (Insulpac, Wangen, $\mathrm{CH}$ ) for thermal isolation. Electrical heating is used for the starting up procedure and for compensating heat losses [7].

\subsection{Experimental setup}

The installation is shown schematically in Fig. 2. It consists of a feed section for steam reforming (1), for the total oxidation of methanol (2), the two-passage micro-structured reactor (3), and the analysis section (4) with a quadrupole mass spectrometer (QMG422, Inficon) and an IR $\mathrm{CO}_{\mathrm{x}}$ detector (Ultramat 22P, Siemens).

The feed section for the steam reforming allows switching between inert (argon) and reactant feed, consisting of methanol (37.7 mol\%) water (45.3 mol\%), and argon (17.0 mol\%). Liquids were dosed with a liquid flow meter and evaporated with a Controlled Evaporation Mixer (Bronkhorst High-Tech B.V.). Argon acts as an evaporating agent and as internal standard. The feed section for the total oxidation of methanol allows to switch between inert (nitrogen) and reactant feed consisting of methanol (10.0 mol\%), oxygen (18.9 mol\%), and inert (71.1 mol\% nitrogen).

Reactants are measured continuously with the mass spectrometer. Since the response factor of the mass spectrometer change with time, daily calibrations are performed.

Carbon oxides, produced in the steam reforming reaction, are measured with the IR detector after condensation of methanol and water in a cooled heat-exchanger.

To avoid condensation of reactants in the tubing of the installation, all lines are maintained at $150^{\circ} \mathrm{C}$. The mass spectrometer is also heated to $150{ }^{\circ} \mathrm{C}$ to minimize adsorption of water and methanol on the walls of the analysis chamber.

\section{Results and discussion}

For the proper design of the micro-structured reactor, kinetic models for the steam reforming as well as for the total combustion of methanol are indispensable. The reaction kinetics was studied under isothermal conditions in a micro-structured reactor with 2500 parallel channels.

\subsection{Methanol steam reforming}

Over copper based catalysts the following reaction mechanism is proposed by numerous authors [6,11-14]:

$$
\begin{aligned}
& 2 \mathrm{CH}_{3} \mathrm{OH} \rightleftarrows \mathrm{HCOOCH}_{3}+2 \mathrm{H}_{2} \\
& \mathrm{HCOOCH}{ }_{3}+\mathrm{H}_{2} \mathrm{O} \rightleftarrows \mathrm{HCOOH}+\mathrm{CH}_{3} \mathrm{OH} \\
& \mathrm{HCOOH} \rightleftarrows \mathrm{CO}_{2}+\mathrm{H}_{2}
\end{aligned}
$$

$\mathrm{CO}$ is mainly produced by the consecutive (reverse) water-gas shift reaction:

$\mathrm{CO}_{2}+\mathrm{H}_{2} \rightleftarrows \mathrm{CO}+\mathrm{H}_{2} \mathrm{O}$

To improve the hydrogen and $\mathrm{CO} 2$ selectivity, it is beneficial to increase the steam to methanol ratio. The benefit is somewhat offset by the increased heating requirement for vaporizing the additional water in the feed [5,7].

The kinetics of the steam reforming over the used catalyst can be best described by the following empirical relationship [9]:

$$
\begin{aligned}
& -R_{\mathrm{MeOH}}=k \mathrm{C}_{\mathrm{MeOH}}^{n_{1}} C_{\mathrm{H}_{2} \mathrm{O}}^{n_{2}} C_{\mathrm{H}_{2}}^{n_{3}} \\
& n_{1}=0.7 ; n_{2}=0.1 ; n_{3}=-0.2
\end{aligned}
$$




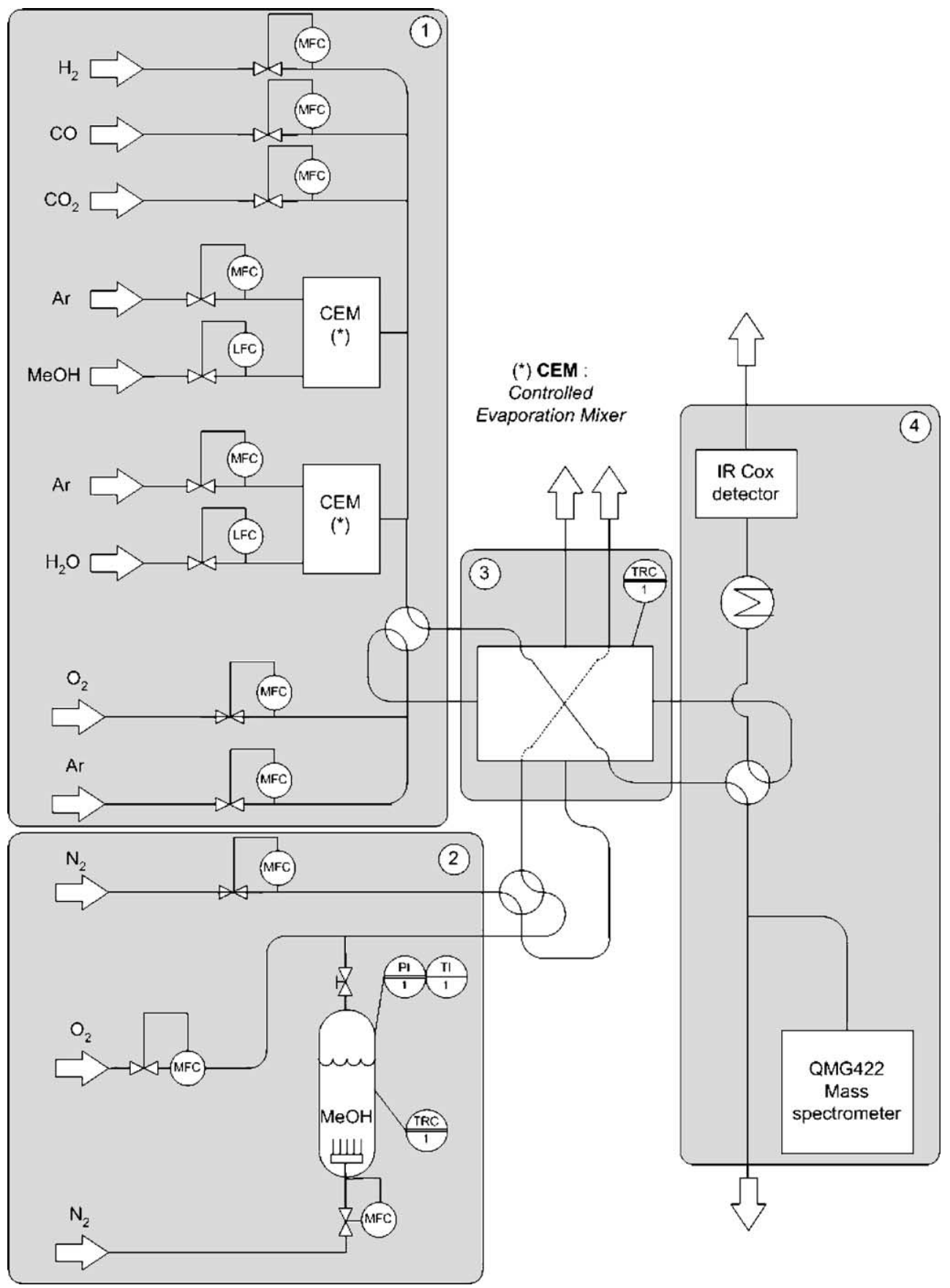

Fig. 2. Experimental set-up. (1) Feed section of the steam reforming; (2) feed section of the total oxidation; (3) two-passage micro-structured reactor; (4) analysis section.

The activation energy was found to be $77 \mathrm{~kJ} / \mathrm{mol}$ in the temperature range of $200<T<300^{\circ} \mathrm{C}$.

The reaction is accompanied by an important volume change (Eq. (1)), which can not be neglected as the feed concentrations of the reactants are quite high. Therefore, the expansion of the reaction mixture with increasing methanol conversion must be considered for the evaluation of the experimental results and for the reactor design. The expansion factor [15] depends on the water to methanol and the inert (argon) to methanol ratio $M_{\mathrm{H}_{2} \mathrm{O}}$ and $M_{\text {in }}$, respectively.

$\alpha=\frac{2}{1+M_{\mathrm{H}_{2} \mathrm{O}}+M_{\text {in }}}$

with

$M_{\mathrm{H}_{2} \mathrm{O}}=\frac{F_{\mathrm{H}_{2} \mathrm{O}, 0}}{F_{\mathrm{MeOH}, 0}}, \quad M_{\mathrm{in}}=\frac{F_{\mathrm{Ar}, 0}}{F_{\mathrm{MeOH}, 0}}$

where $F_{i, 0}$ is the molar feed rate of the compound $i$. 


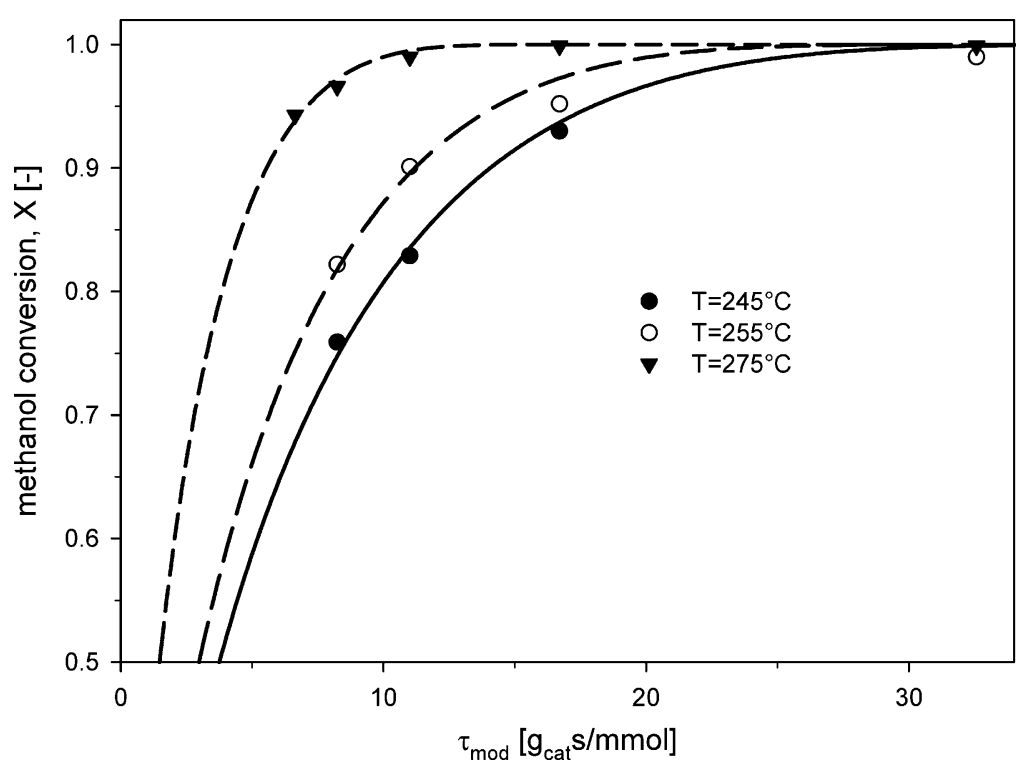

Fig. 3. Methanol conversion for the steam reforming as function of the modified space time. Comparison between predicted and measured results. Experimental conditions: $M_{\mathrm{H}_{2} \mathrm{O}}=1.0, M_{\text {in }}=0.40, m_{\text {cat }}=475 \mathrm{mg}$, flow rate: $50-250 \mathrm{ml}(\mathrm{STP}) / \mathrm{min}$.

In the present study, the molar water to methanol ratio varies between 1 and 1.5 and $M_{\text {in }}$ is typically $0.4-0.5$.

The material balance for an ideal tubular reactor is hence given by Eq. (8).

$\frac{\mathrm{d} X}{\mathrm{~d} \tau_{\mathrm{bmod}}}=k v_{\mathrm{H}_{2}}^{n_{3}} C_{\mathrm{MeOH}, 0}^{\sum n_{i}} \frac{(1-X)^{n_{i}}\left(M_{\mathrm{H}_{2} \mathrm{O}}-X\right)^{n_{2}} X^{n_{3}}}{(1+\alpha X)^{\sum n_{i}}}$

The modified space time $\left(\tau_{\mathrm{mod}}\right)$ is defined as ratio of the catalyst mass $(W)$ to the molar feed of methanol $\left(F_{\mathrm{MeOH}, 0}\right)$.

$\tau_{\mathrm{bmod}}=\frac{W}{F_{\mathrm{MeOH}, 0}}$
In Fig. 3 predicted and measured conversions are given as function of the modified space time for different reaction temperatures.

The concentration of $\mathrm{CO}$ at the reactor outlet is relatively low up to methanol conversions of $X=0.9$ as can be seen in Fig. 4, where the measured $\mathrm{CO}_{2}$ selectivity (Eq. (10)) is plotted against conversion for a reactor temperature of $260^{\circ} \mathrm{C}$.

$S_{\mathrm{CO}_{2}}=\frac{C_{\mathrm{CO}_{2}}}{C_{\mathrm{CO}_{2}}+C_{\mathrm{CO}}}$

The experimental results are compared to the equilibrium selectivity calculated for the water-gas-shift reaction

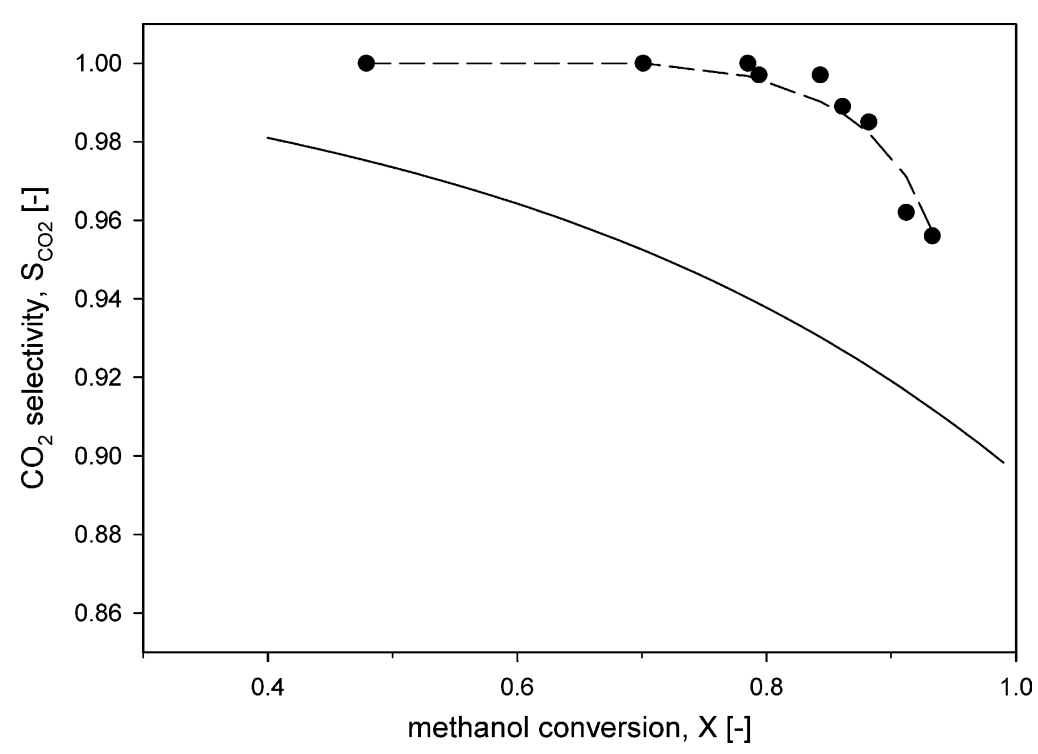

Fig. 4. $\mathrm{CO}_{2}$ selectivity vs. methanol conversion. Experimental results and equilibrium values. For experimental conditions, see Fig. 3. 
(Eq. (4)). The experimentally observed selectivity is always higher than the equilibrium values indicating that $\mathrm{CO}$ is produced in a consecutive reaction step as mentioned above. The concentration of $\mathrm{CO}$ is in the order of $1-2$ vol.\% for methanol conversions of about $90 \%$.

As $\mathrm{CO}$ is formed by the reverse water-gas-shift reaction (Eq. (4)), hydrogen is consumed in a stoichiometric amount. In consequence, hydrogen selectivity corresponds to the selectivity of $\mathrm{CO}_{2}$ and the $\mathrm{H}_{2}$ yield is $1-2 \%$ lower than the methanol conversion.

\subsection{Total oxidation of methanol}

The catalytic combustion of methanol (Eq. (2)) is used to provide the necessary heat consumed by the methanol reforming. To prevent deactivation of the copper based reforming catalyst, the reaction temperature should be lower than $270^{\circ} \mathrm{C}$. The coupled oxidation reaction has to be carried out in the same temperature range. In addition, the catalyst activity must be high enough to guarantee complete conversion of methanol. The developed cobalt oxide catalyst deposited on the walls of the micro-channels satisfies the mentioned demands. As shown in Fig. 5, methanol conversions higher than $99 \%$ are attained at space times $\tau_{\text {mod }} \geq 26 \mathrm{~g}_{\text {cat }} \mathrm{s} / \mathrm{mmol}$ at reaction temperatures $T \geq 250^{\circ} \mathrm{C}$. The kinetics of the total oxidation of methanol (RMeOH) can be described satisfactorily by the following power law:

$-R_{\mathrm{MeOH}}=k_{\mathrm{TOX}} C_{\mathrm{MeOH}}^{2 / 3} C_{\mathrm{MeOH}}^{2 / 3}$

Introducing the initial molar ratio of oxygen to methanol $\left(M_{\mathrm{O}_{2}}\right)$ results in Eq. (12) used for the design of the micro- channel reactor:

$$
\begin{aligned}
\frac{\mathrm{d} X}{\mathrm{~d} \tau_{\mathrm{bmod}}}= & -R_{\mathrm{MeOH}} \\
= & k_{\mathrm{TOX}} v^{2 / 3} C_{\mathrm{MeOH}, 0}^{2 / 3}(1-X)^{2 / 3} \\
& \times C_{\mathrm{MeOH}, 0}^{2 / 3}\left(M_{\mathrm{O}_{2}}-X\right)^{2 / 3}
\end{aligned}
$$

The activation energy is estimated from the Arrhenius plot as presented on Fig. 6. It was found to be approximately $130 \mathrm{~kJ} / \mathrm{mol}$ in the interesting temperature range of $230-270{ }^{\circ} \mathrm{C}$.

\subsection{Coupled steam reforming/total oxidation}

Steam reforming and total oxidation of methanol are combined in the two-passage reactor used in the co-current mode. At a temperature of $260^{\circ} \mathrm{C}$, measured in the center of the reactor, the catalytic oxidation leads to total conversion of methanol. The methanol conversion for steam reforming as function of the modified space time is shown in Fig. 7. The experimental results are compared with predicted values for $260^{\circ} \mathrm{C}$. The experimentally observed conversions are slightly lower compared to the predicted one. This can be explained by the axial temperature profile. As shown in the inset of Fig. 7, the temperature at the reactor entrance and outlet is $1-2.5^{\circ} \mathrm{C}$ lower compared to the center.

On Fig. 8 the experimentally determined $\mathrm{CO}_{2}$ selectivity versus methanol conversion is shown. As for the isothermal reactor (Fig. 4), selectivities are considerably higher compared to the equilibrium values calculated for the water-gas-shift reaction (Eq. (4)). The selectivities obtained

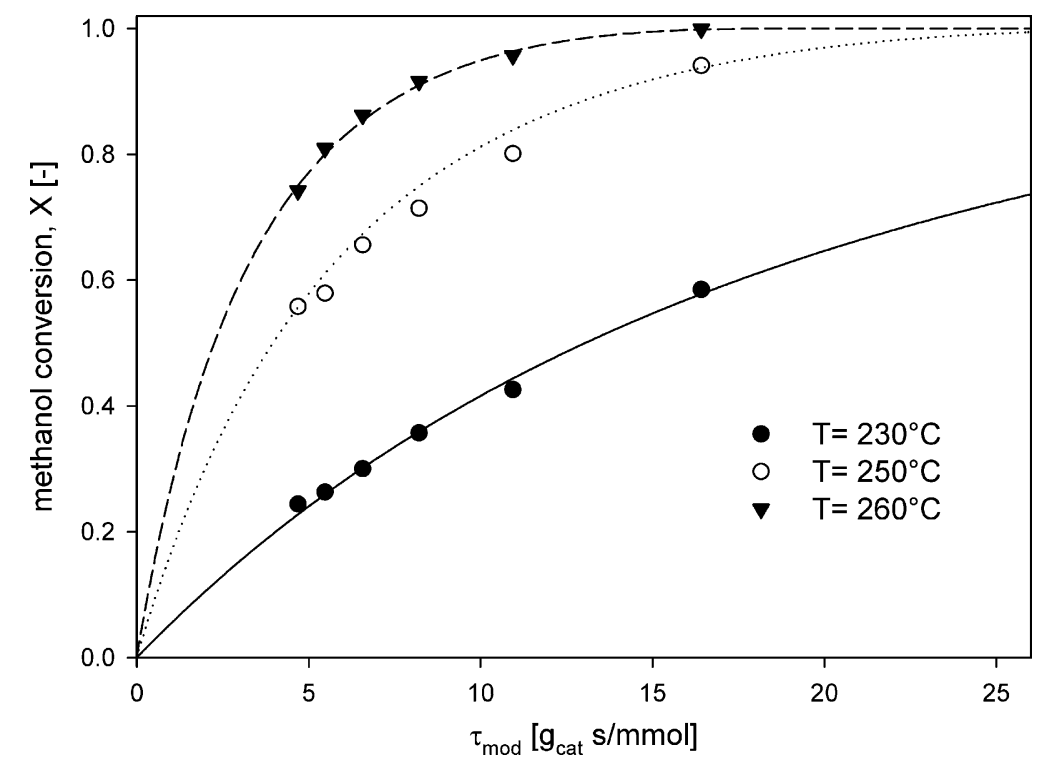

Fig. 5. Total oxidation of methanol vs. modified space time. Comparison of predicted to experimental values. Experimental conditions: $m_{\mathrm{cat}}: 57 \mathrm{mg}$; concentration: 10 vol. $\% \mathrm{CH}_{3} \mathrm{OH}, 18.9$ vol. $\% \mathrm{O}_{2}, 71.1 \mathrm{vol} . \% \mathrm{~N}_{2}$. 


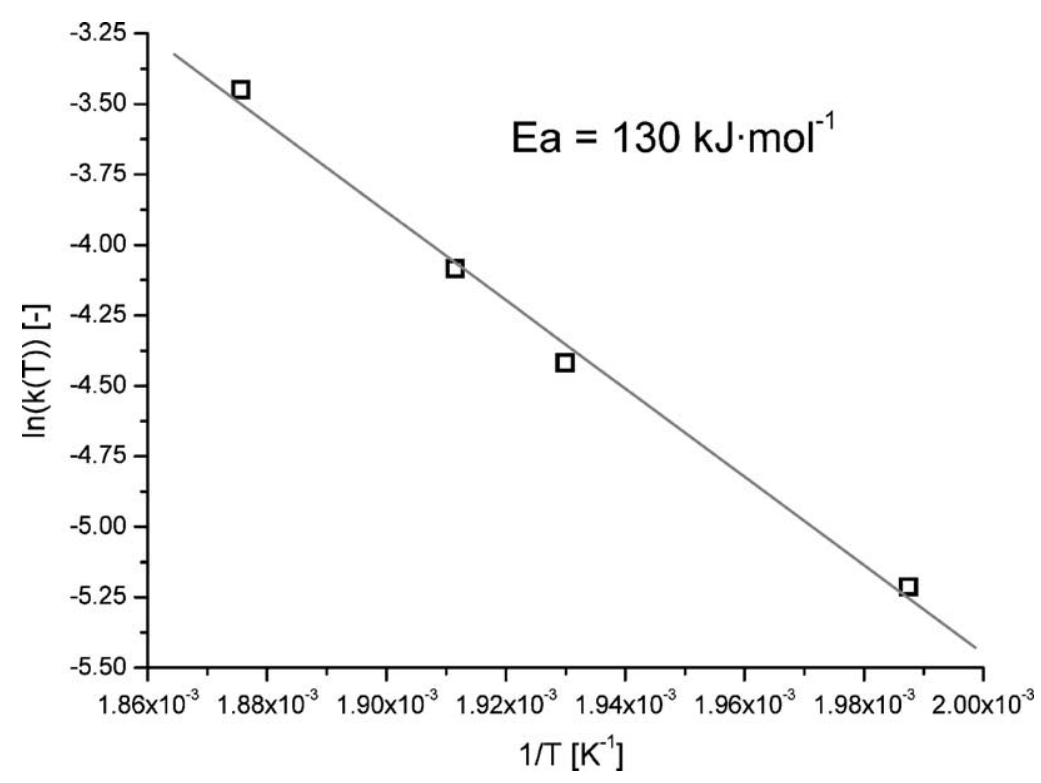

Fig. 6. Total oxidation of methanol. Rate constant as function of temperature.

in the autothermal reactor are roughly $1 \%$ lower compared to the values observed in the isothermal reactor.

\subsection{Dynamic behavior of the autothermal reactor}

The dynamic behavior of the reactor is of crucial importance for hydrogen production in mobile systems. The dynamics of the coupled reactors are studied by switching the feed for total oxidation between inert gas and the reaction mixture. Reaction temperature in the center of the reactor and transient methanol conversion are plotted on Fig. 9. When switching from inert to the methanol/oxygen mixture a temperature increase of $10^{\circ} \mathrm{C}$ within $60 \mathrm{~s}$ is observed. Stopping the TOX reaction leads to a temperature decrease of $10^{\circ} \mathrm{C}$ within approximately $90 \mathrm{~s}$. In parallel to the temperature variation the methanol conversion in the steam-reformer changes. It is important to note that the conversion follows immediately the temperature profile after about 40 min of time on stream. Therefore, instantaneous methanol conversion can be predicted based on the kinetic model presented.

The dynamic behavior is mainly determined by the thermal inertia of the reactor, which is quite important for the experimental reactor due to its housing.

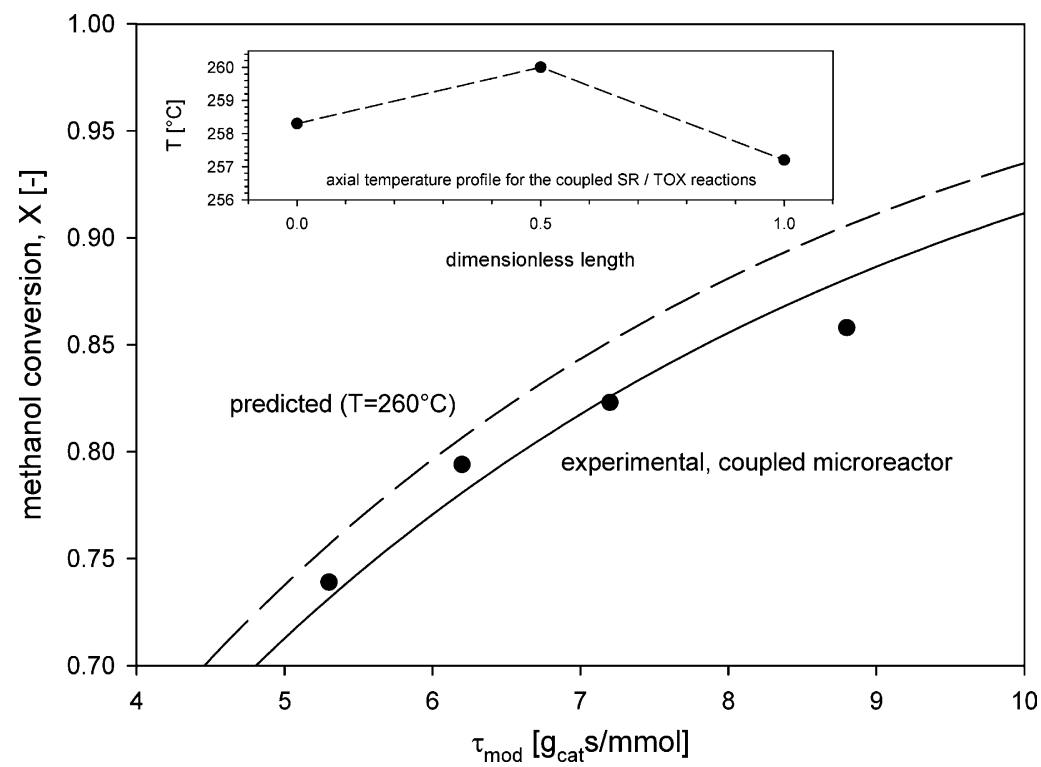

Fig. 7. Methanol conversion for steam reforming in the two-passage reactor coupled with total oxidation. Experimental conditions: $m_{\text {cat }}=206 \mathrm{mg}$, concentration: 37.7 vol. $\% \mathrm{CH}_{3} \mathrm{OH}, 45.3$ vol. $\% \mathrm{O}_{2}, 17.0$ vol. $\%$ Ar. 


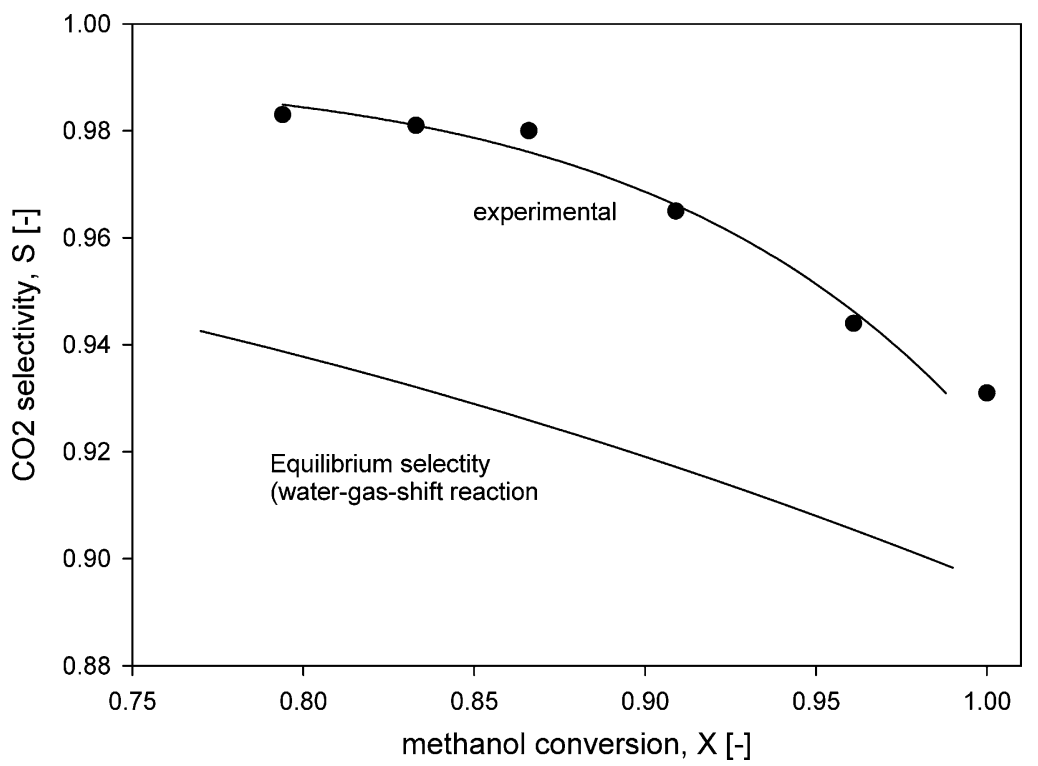

Fig. 8. Selectivity of $\mathrm{CO}_{2}$ as function of methanol conversion for co-current flow and total oxidation in the second reactor. Reaction-temperature: $260{ }^{\circ} \mathrm{C}$. For experimental conditions, see Fig. 7.

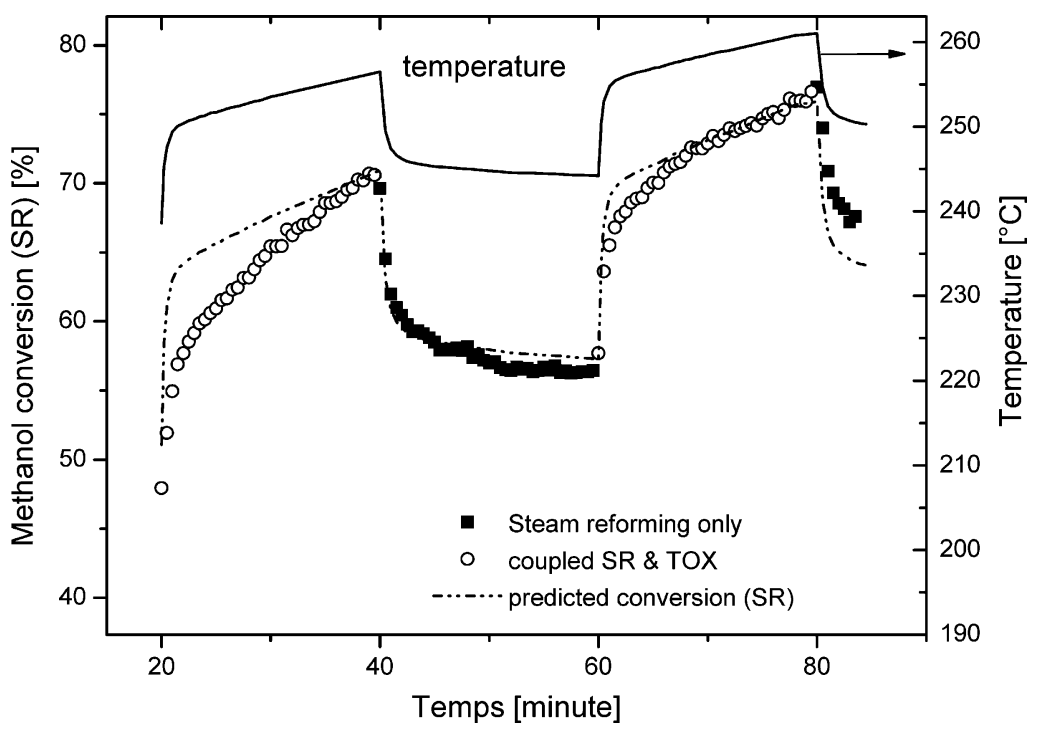

Fig. 9. Reactor-temperature and methanol conversion for steam reforming as function of time. Switch between inert gas and reaction mixture for the TOX reactor. Experimental conditions: SR: $m_{\text {cat }}=206 \mathrm{mg}$, concetration: $37.7 \mathrm{vol} . \% \mathrm{CH} 3 \mathrm{OH}, 45.3 \mathrm{vol} . \% \mathrm{O}_{2}, 17.0$ vol. $\%$ Ar; $\mathrm{TOX}: m_{\text {cat }}=434 \mathrm{mg}$, concentration: 10 vol. $\% \mathrm{CH}_{3} \mathrm{OH}, 18.9$ vol. $\% \mathrm{O}_{2}, 71.1$ vol. $\% \mathrm{~N}_{2}$.

\section{Conclusion}

A two-passage reactor was used to couple two reactions: steam reforming of methanol, producing hydrogen, and total oxidation of methanol, producing heat. Different catalysts were used: Commercially available copper based catalyst for the steam reforming and a cobalt based catalyst for total oxidation. Special methods were developed to coat the catalysts on the wall of the micro-channels. The kinetics of both reactions were studied independently in an isothermal micro-structured reactor.
The exothermal and endothermal were coupled in the developed two-passage reactor under co-current conditions. The axial temperature profiles never exceeded $2.5^{\circ} \mathrm{C}$. Therefore, the kinetic models could be used to predict the steady state and the dynamic reactor behavior.

\section{Acknowledgements}

The authors are grateful to Ian Walford for his precious help in the laboratory. The authors gratefully acknowledge 
the "Bundesministerium für Bildung und Forschung", Germany for their financial support (Contract 03D0072C/0). We also thank Süd-Chemie for providing the catalyst.

\section{References}

[1] A. Rouge, B. Spoetzl, S. Schenk, K. Gebauer, A. Renken, Microchannel reactors for fast cperiodic operation: the catalytic dehydration of isopropanol, Chem. Eng. Sci. 56 (4) (2001) 1419-1427.

[2] A. Rouge, A. Renken, Forced periodic temperature oscillations in micro-channel reactors, in: Proceedings of the Fifth International Conference on Microreaction Engineering (IMRET 5), Springer, Strasbourg, 2001, pp. 230-239.

[3] L.F. Brown, A comparative study of fuels for on-board hydrogen production for fuel-cell-powered automobiles, Int. J. Hydrogen Energy 26 (2001) 381-397.

[4] M.S. Spencer, The role of zinc oxide in $\mathrm{Cu} / \mathrm{ZnO}$ catalysts for methanol synthesis and the water-gas shift reaction, Top. Catal. 8 (1999) 259-266

[5] J.C. Amphlett, K.A.M. Creber, J.M. Davis, R.F. Mann, B.A. Peppley, D.M. Stokes, Hydrogen production by steam reforming of methanol for polymer electrolyte fuel cells, Int. J. Hydrogen Energy 19 (2) (1994) 131-137.

[6] C.J. Jiang, D.L. Trimm, M.S. Wainwright, N.W. Cant, Kinetic study of steam reforming of methanol over copper-based catalysts, Appl. Catal. A: General 93 (1993) 245-255.
[7] P. Reuse, Production d'hydrogène dans un réacteur microstructuré. Couplage themique entre le steam reforming et l'oxydation totale du méthanol, EPF-Lausanne No. 2830, 2003.

[8] K. Haas-Santo, O. Görke, P. Pfeifer, K. Schubert, Catalyst coatings for microstructure reactors, Chimia 56 (11) (2002) 605-610.

[9] P. Reuse, L. Kiwi-Minsker, A. Renken, Catalyst coating in microstructured reactors for methanol steam reforming: kinetics, in: Abstracts of the Fifth International Conference on Microreaction Engineering (IMRET 5), DECHEMA, Strasbourg, 2001, pp. 169-170.

[10] I. Yuranov, N. Dunand, L. Kiwi-Minsker, A. Renken, Metal grids with high-porous surface as structured catalysts: preparation, characterization and activity in propane total oxidation, Appl. Catal. B: Environ. 36 (3) (2002) 183-191.

[11] C.J. Jiang, D.L. Trimm, M.S. Wainwright, N.W. Cant, Kinetic mechanism for the reaction between methanol and water over a $\mathrm{Cu}-$ $\mathrm{ZnO}-\mathrm{Al}_{2} \mathrm{O}_{3}$ catalyts, Appl. Catal. A: General 97 (1993) 145-158.

[12] B.A. Peppley, J.C. Amphlett, L.M. Kearns, R.F. Mann, Methanol steam reforming on $\mathrm{Cu} / \mathrm{ZnO} / \mathrm{Al}_{2} \mathrm{O}_{3}$. Part 2: A comprehensive kinetic model, Appl. Catal. A: General 179 (1999) 31-49.

[13] B.A. Peppley, J.C. Amphlett, L.M. Kearns, R.F. Mann, Methanol steam reforming on $\mathrm{Cu} / \mathrm{ZnO} / \mathrm{Al}_{2} \mathrm{O}_{3}$. Part 1: The reaction network, Appl. Catal. A: General 179 (1999) 21-29.

[14] J.P. Breen, J.R.H. Ross, Methanol reforming for fuel-cell applications: development of zirconiacontaining $\mathrm{Cu}-\mathrm{Zn}-\mathrm{Al}$ catalysts, Catal. Today 51 (1999) 521-533.

[15] M. Baerns, H. Hoffmann, A. Renken, Chemische Reaktionstechnik. Lehrbuch des Technischen Chemie, Band 1, Georg Thieme Verlag, Stuttgart, Germany, 1999. 